\title{
DIAGNÓSTICO DO GRAU DE DESENVOLVIMENTO \\ E DOS FATORES DE IMPACTO NA IMPLEMENTAÇÃO DA INDÚSTRIA 4.0 NO SETOR INDUSTRIAL CATARINENSE
}

\author{
Carlos Ernani Fries \\ Universidade Federal de Santa Catarina/UFSC \\ Caixa postal 476-88040-900 \\ carlos.fries@ufsc.br \\ Ricardo Müller Filho \\ Universidade Federal de Santa Catarina/UFSC \\ Caixa postal 476- 88040-900 \\ rmullerfilho@gmail.com \\ Danieli Ferentz \\ Universidade Federal de Santa Catarina/UFSC \\ Caixa postal 476-88040-900 \\ dani12ferentz@hotmail.com \\ Fernanda Christmann \\ Universidade Federal de Santa Catarina/UFSC \\ Caixa postal 476- 88040-900 \\ fe.christmann.fc@gmail.com
}

\section{RESUMO}

O setor industrial desempenha papel fundamental na consolidação de uma economia forte e sustentável, funcionando como fonte de avanços tecnológicos e de crescimento em longo prazo. No entanto, nos últimos anos no Brasil, o setor está perdendo precocemente participação na composição do Produto Interno Bruto (PIB), fenômeno este conhecido como desindustrialização. Como alternativa para retomar o crescimento do setor industrial e tornálo, novamente, competitivo em um cenário global digitalizado, encontram-se os princípios da Indústria 4.0. Defendida por muitos estudiosos como a quarta Revolução Industrial, a Indústria 4.0, ou Manufatura Avançada, tem por objetivo integrar as tecnologias digitais de comunicação e informação aos sistemas produtivos, gerando ganhos exponenciais por toda a cadeia de valor. Este trabalho visa contribuir com o processo de digitalização da Indústria em Santa Catarina, através do diagnóstico atual de implementação da Indústria 4.0 no setor industrial catarinense e da identificação dos desafios e oportunidades durante esse processo. Para isso, são aplicadas técnicas estatísticas em dados provenientes das indústrias do estado de Santa Catarina, entre o período de março de 2017 a maio de 2017. Os resultados obtidos mostram que muitos setores da indústria catarinense já estão incorporando as tecnologias da Indústria 4.0 ao seu processo produtivo, tais como Big Data e Internet das Coisas. Identificou-se, também, o alto custo de investimento inicial, a falta de infraestrutura em TI e a falta de mão de obra qualificada como os principais entraves à Indústria 4.0 no estado. Essas constatações podem auxiliar o setor industrial catarinense, bem como outros estados da federação, a tomar medidas mais efetivas no auxílio às empresas durante esse processo de industrialização que, em muitos países, já está bastante consolidado.

Palavra-chave: Indústria 4.0; Desindustrialização; Tecnologias Digitais. 


\begin{abstract}
The industrial sector plays a fundamental role in the consolidation of a strong and sustainable economy, functioning as a source of technological advancements and long-term growth. However, in recente years in Brazil, the sector is losing participation in the composition of the Gross Domestic Product (GDP), phenomenon known as deindustrialisation. As an alternative to restore growth in the industrial sector and make it competitive again in a digitized global scenario, are the principles of Industry 4.0. Defended by many scholars as the fourth Industrial Revolution, Industry 4.0, or Advanced Manufacturing, aims to integrate digital information and communication technologies to the productive systems, generating exponential gains throughout the value chain. This work aims to contribute with the digitalization process of the Industry in Santa Catarina, through the current diagnosis of implementation of Industry 4.0 in the industrial sector of the state and the identification of the challenges and opportunities during this process. For this reason, are applied statistical techniques on data from the state of Santa Catarina industries, in the period from March 2017 to May 2017. The results obtained show that many sectors of the state industry are already incorporating the technologies of the Industry 4.0 to its productive process, such as Big Data and Internet of Things. It was also identified the high cost of initial investment, the lack of IT infrastructure and the lack of skilled labor as the main obstacles to Industry 4.0 in the state. These findings may help the industrial sector of the Santa Catarina state to take more effective measures in aid to companies during this industrialisation process that, in many countries, is already quite well established.
\end{abstract}

Keywords: Industry 4.0; Deindustrialization; Digital technologies.

\title{
Como Citar:
}

FRIES, Carlos Ernani; MULLER F., Ricardo; FERENTZ, Danieli; CHRISTMANN, Fernanda. Diagnóstico do grau de desenvolvimento e dos fatores de impacto na implementação da Indústria 4.0 no setor industrial catarinense. In: SIMPÓSIO DE PESQUISA OPERACIONAL E LOGÍSTICA DA MARINHA, 19., 2019, Rio de Janeiro, RJ. Anais [...]. Rio de Janeiro: Centro de Análises de Sistemas Navais, 2019. 


\section{INTRODUÇÃO}

O setor industrial brasileiro vem perdendo, nos últimos anos, participação na composição do Produto Interno Bruto (PIB) do país. A Figura 1 mostra que, a partir do ano 2013, o setor industrial brasileiro perdeu aproximadamente seis pontos percentuais na participação do PIB do país, evidenciando um grave e acelerado processo de desindustrialização (DEPECON-FIESP, 2015).

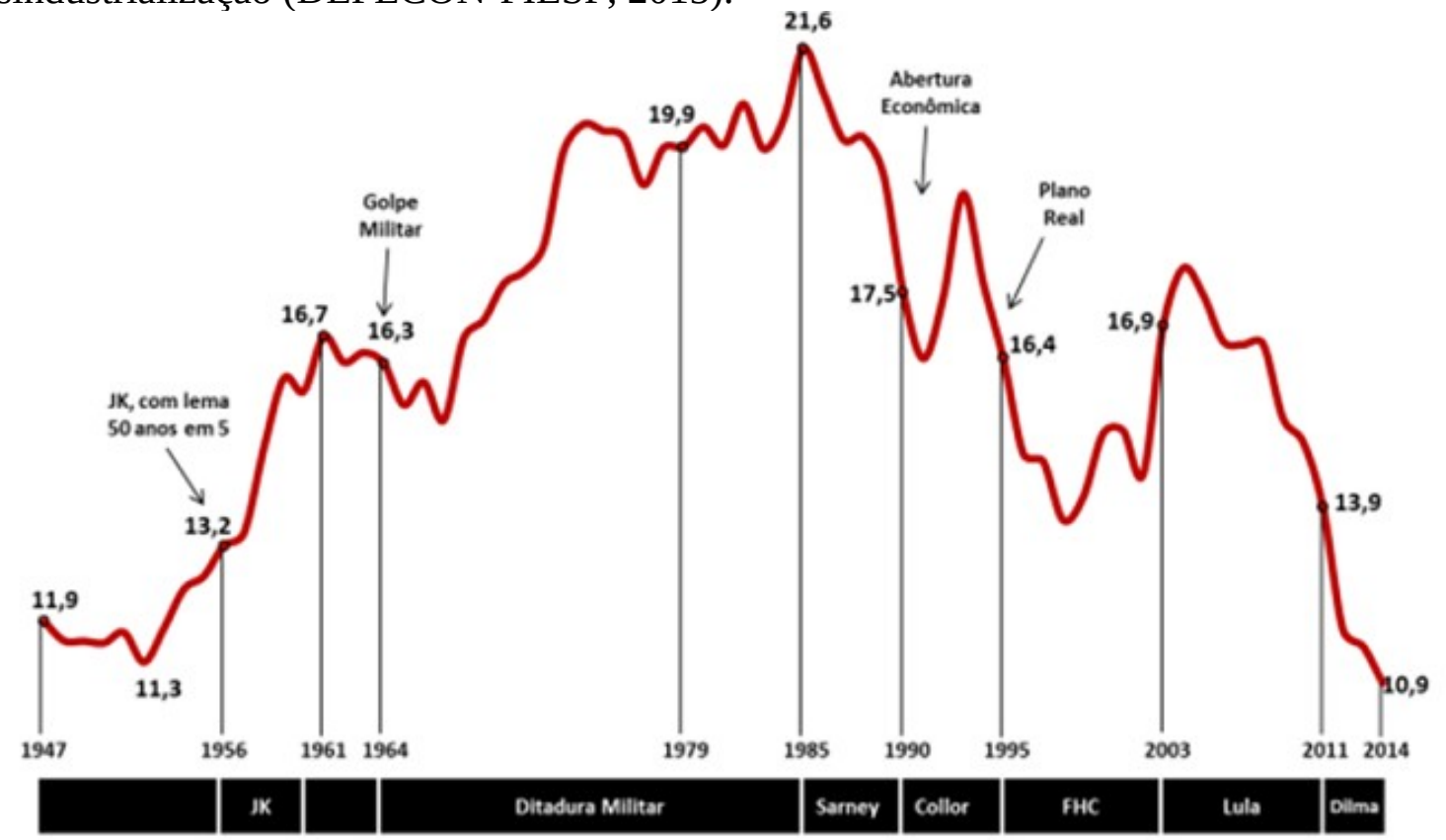

Figura 1: Percentual de participação do setor industrial brasileiro no PIB Fonte: IBGE, Elaboração DEMOMTEC/FIESP (2015)

Segundo estudos do Departamento de Competitividade e Tecnologia (DEPECON, 2015) quanto maior a participação da indústria no PIB de um país, maior tende a ser seu crescimento econômico. Afirma ainda que o investimento na industrialização consiste em uma estratégia forte para o Brasil elevar o nível de renda per capita. Pelo contrário, o país está passando por um processo reverso - a desindustrialização. Esta desindustrialização precoce provoca impactos negativos na economia do país visto que, para se chegar a um alto nível de renda per capita, é preciso aumentar a participação da indústria de transformação no PIB pois o crescimento desta se torna o propulsor para o desenvolvimento econômico dos outros setores da economia (DEPECON-FIESP, 2015).

Em Santa Catarina, de acordo com a Federação das Indústrias do Estado de Santa Catarina (FIESC), o processo de desindustrialização acompanhou o panorama nacional. Isto é, o setor industrial no estado perdeu precocemente espaço para o setor de serviços. Tal fato causou perdas significativas para o crescimento da economia. Em anos recentes muito tem sido ressaltado que, a exemplo de experiências maduras com a digitalização dos processos na indústria, um caminho promissor para retomada do crescimento do setor industrial, e torná-lo novamente competitivo, seria a implementação dos princípios da Indústria 4.0.

Este trabalho objetiva diagnosticar a situação corrente e as dificuldades do processo de transformação digital da Indústria 4.0 em Santa Catarina. Os resultados foram obtidos por meio de técnicas estatísticas com o auxílio de dados de natureza categórica, levantados junto a empresas de setores industriais diversos. Estes resultados podem contribuir para a aceleração do processo de digitalização da indústria do estado - ou mesmo para outros estados da federação - e com isto dar maior competitividade ao setor. 


\section{CONTEXTUALIZAÇÃO DO TEMA}

Uma análise conceitual dos sistemas produtivos e sua evolução até a conceito da Indústria 4.0 atual é apresentado nesta seção. Neste contexto descreve-se as características da indústria em Santa Catarina, principalmente sobre sua importância para o cenário nacional e internacional. O fenômeno da desindustrialização que também acompanha o setor no estado é analisado sob a ótica de identificar as potencialidades e desafios que a Indústria 4.0 oferece se esta estiver sendo implementada num grau elevado.

\subsection{A INDÚSTRIA 4.0 E A EVOLUÇÃo DOS SISTEMAS PRODUTIVOS INDUSTRIAIS}

A Indústria 4.0 representa um conjunto de tecnologias digitais de informação e comunicação, orientadas através de sistemas de produção ciber-físicos (Cyber-Physical Production Sistems-CPPS's), que, nos últimos anos, estão ganhando espaço no ambiente industrial. Estes sistemas possuem integram instalações produtivas, sistemas de armazenagem, sistemas logísticos e, até mesmo, requisitos sociais para a criação de uma cadeia global de valor (WANG et al., 2016).

A Figura 2 ilustra a evolução tecnológica responsável pelas revoluções industriais, comparando-as com um aumento no grau de complexidade e produtividade. Ilustra, também, as principais tecnologias responsáveis por cada salto tecnológico. Inicia-se com os primeiros dispositivos mecânicos, marco da primeira Revolução Industrial, passando pelas linhas de produção e os primeiros sistemas autônomos de controle, até os sistemas de produção Ciber-físicos atuais, responsáveis pelo controle das fábricas inteligentes (LASI et al., 2014). A curva representada na figura simboliza o crescimento exponencial em complexidade de produção e produtividade que as indústrias sofreram ao longo das revoluções industriais.

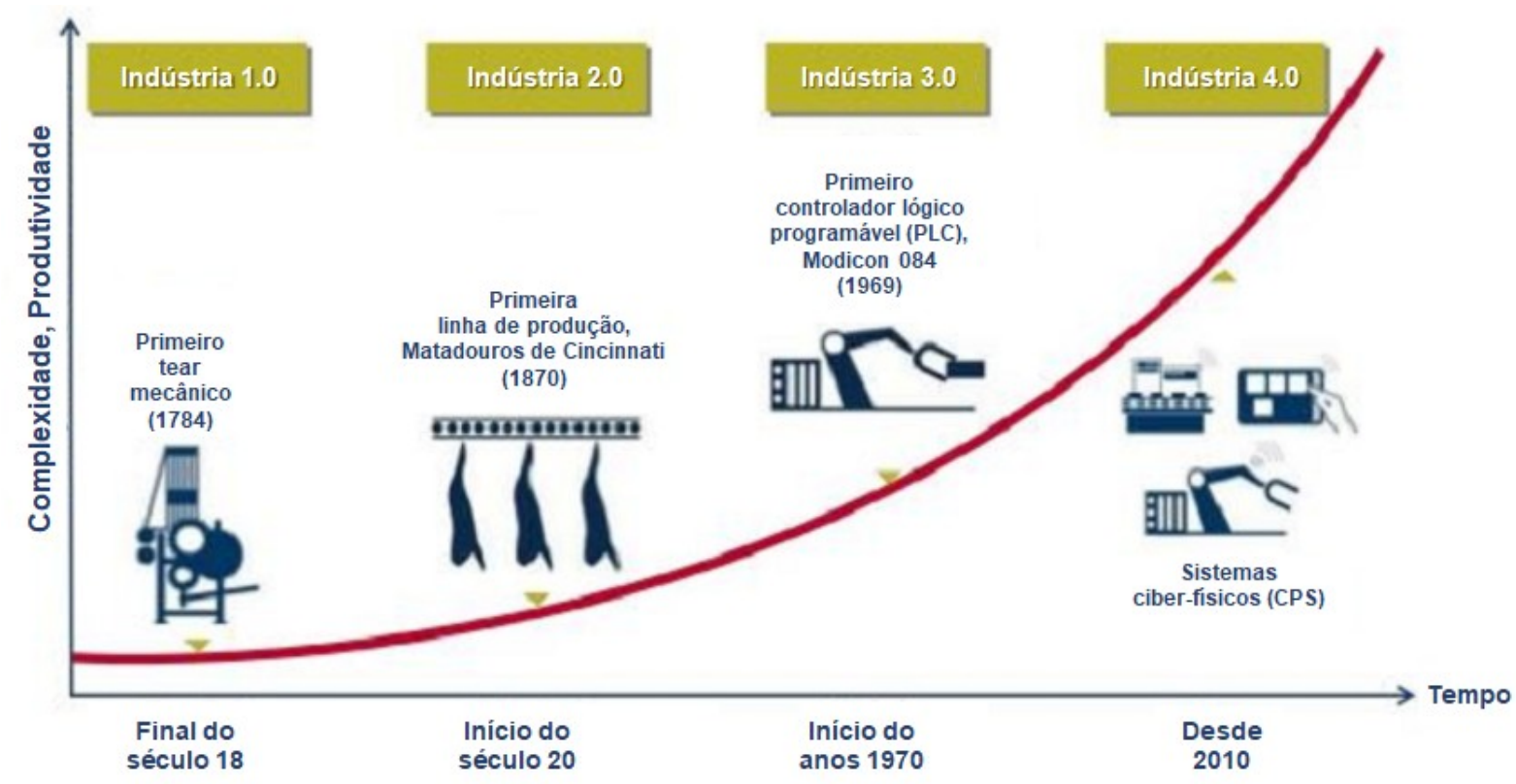

Figura 2: A evolução das tecnologias aplicadas à indústria

Fonte: adaptado de ROBERT BOSCH GMBH (2016) definidas:

Segundo Geissbauer et al. (2016), a Indústria 4.0 é conduzida por três frentes bem

i. digitalização e Integração das cadeias de valor verticais e horizontais;

ii. digitalização da oferta de produtos e serviços;

iii. modelos de negócio e acesso de clientes digitais. 
Na Figura 4 está representada a visão das três frentes da Indústria 4.0 de Geissbauer et al. (2016). Pode-se perceber, também, um conjunto de tecnologias digitais que, pela ilustração, circundam as características da Indústria 4.0. Esse conjunto de tecnologias compõe a infraestrutura tecnológica necessária para gerir a cadeia de valor das empresas e possibilitar a digitalização e integração das organizações.

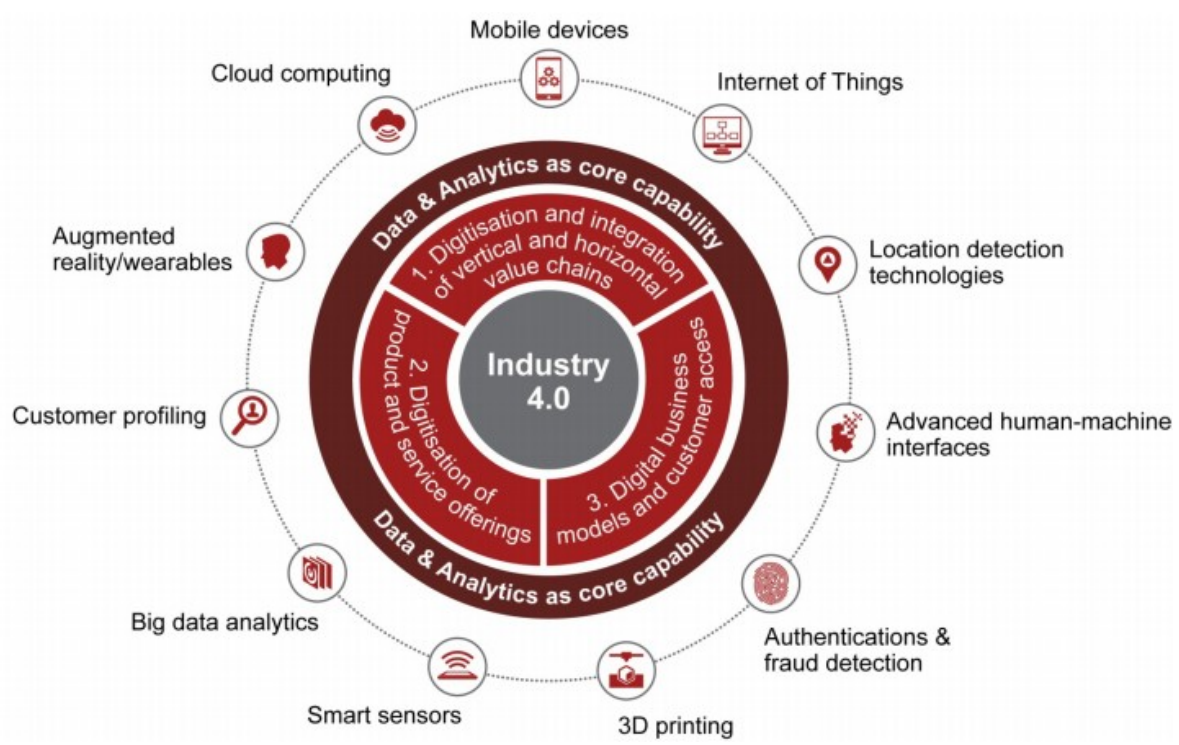

Figura 3 - Representação do modelo da Indústria 4.0

Fonte: GEISSBAUER et al., 2016

A Indústria 4.0 digitaliza e integra processos de forma vertical em toda a organização, desde o desenvolvimento e compra de produtos até a manufatura, logística e serviços. Todos os dados sobre o processo operacional, eficiência de processos e gerenciamento de qualidade, bem como o planejamento de operações estão disponíveis em tempo real, suportados pela realidade aumentada e otimizados em uma rede integrada (ZEZULKA et al., 2016). A integração horizontal vai além das operações internas entre fornecedores e clientes e a todos os principais parceiros da cadeia de valor. Ela inclui tecnologias de rastreabilidade e monitoramento que possibilitam, em tempo real, a integração do plano com a execução, passando por todos os parceiros da cadeia. A digitalização de produtos inclui a expansão de produtos já existentes. Isto pode ser feito, por exemplo, através da adição de sensores inteligentes ou dispositivos de comunicação que podem ser usados com ferramentas de análise de dados, bem como a criação de novos produtos digitalizados que se concentram em soluções totalmente integradas. Ao integrar novos métodos de coleta e análise de dados, as empresas são capazes de gerar dados sobre o uso do produto e refiná-los para atender às crescentes necessidades dos clientes finais (GEISSBAUER et al., 2016).

Com a incorporação de soluções da Indústria 4.0 as empresas industriais de destaque expandem sua oferta fornecendo soluções digitais disruptivas, isto é, soluções em serviços completos, orientados a dados e soluções de plataforma integrada. Modelos de negócios digitais disruptivos são frequentemente focados em gerar receitas adicionais e otimizar a interação e o acesso do cliente. Produtos e serviços digitais frequentemente procuram atender clientes com soluções completas em um ecossistema digital distinto (SCHLAEPFER/KOCH, 2015; GEISSBAUER et al., 2016). 


\subsection{O SETOR INDUSTRIAL CATARINENSE}

Santa Catarina possui um parque industrial muito expressivo no contexto nacional, ocupando uma posição de destaque no Brasil. Segundo a Pesquisa Industrial Mensal Produção Física do IBGE (2016), a indústria de transformação catarinense ocupa a quarta posição do País em quantidade de empresas e a quinta em número de trabalhadores. Os segmentos de destaque no estado, empregando o maior número de trabalhadores são os de artigos de vestuário e alimentar, seguidos pelo setor de artigos têxteis (FIESC, 2015). Quanto ao PIB do estado, os dados do último levantamento feito pelo IBGE apontam o estado Santa Catarina como o sexto maior PIB do Brasil, totalizando R\$ 177 bilhões.

$\mathrm{O}$ estado apresenta uma diversidade de polos industriais caracterizados por diferentes atividades econômicas. Apesar dessa diversidade de polos, o perfil econômico das regiões de Santa Catarina é equilibrado. Essa característica multisetorial da indústria permite que o estado se destaque entre os demais, principalmente pelo fato de não depender apenas de poucos setores industriais para compor sua economia (FIESC, 2015).

Em Santa Catarina destacam-se o setor cerâmico, carvão, vestuário e descartáveis plásticos no Sul; alimentar e móveis no Oeste; têxtil, vestuário, naval e produtos de metal no Vale do Itajaí; metalurgia, máquinas e equipamentos, material elétrico, autopeças, plástico, confecções e mobiliário no Norte; madeireiro na região Serrana; e tecnológico na Capital (FIESC, 2015).

Pode-se visualizar na Figura 4 os principais polos industriais do estado, caracterizados pelo número de funcionários e a porcentagem de exportação do setor no estado. Além dos setores já destacados anteriormente, pode-se ainda destacar os segmentos de Máquinas/Equipamentos e Máquinas/Aparelhos e Materiais Elétricos. Encontra-se empresas desse segmento nas mesorregiões do Nordeste e Vale do Itajaí, compondo a força industrial dessas regiões. Fazem parte do seu portfólio produtos de maior valor, podendo-se citar geradores, transformadores, motores elétricos, moto compressores, blocos e cabeçotes para motor, eletrodomésticos, soluções em telecomunicações, redes e segurança (FIESC, 2015).

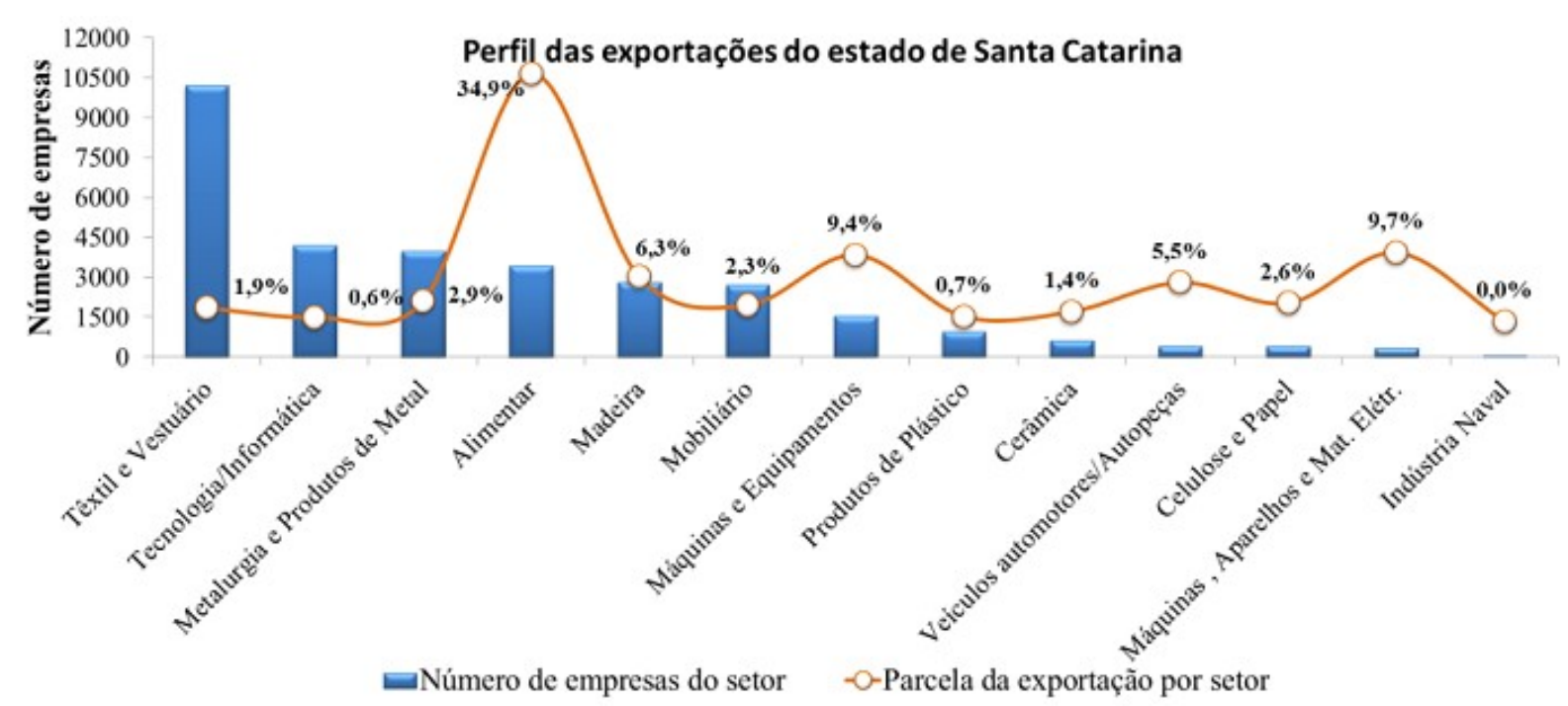

Figura 4: Exportações da Indústria Catarinense

Fonte: adaptado de FIESC, 2015 


\subsection{PROCESSO DE DESINDUSTRIALIZAÇÃo E AS CONSEQUÊNCIAS PARA A INDÚSTRIA CATARINENSE}

Tregenna (2009) define o conceito de desindustrialização como sendo uma situação na qual tanto o emprego industrial como o valor adicionado da indústria se reduzem como proporção do emprego total e do PIB, respectivamente. A problemática do processo de desindustrialização se dá quando o mesmo acontece de forma precoce, isto é, sem que a indústria tenha realizado todas as funções no contexto do desenvolvimento econômico. Observa-se, nesse caso, que a perda relativa do peso da indústria ocorre em um momento onde a renda per capita registra valores baixos aos observados nos países desenvolvidos. Ocorre também na presença de destruição de elos da cadeia produtiva nacional; em correspondência ao crescimento da pauta de insumos, componentes e outras matérias-primas importadas; diante de reduzida importância de segmentos portadores do progresso técnico na estrutura industrial; e de especialização produtiva em segmentos de baixa intensidade tecnológica. Deste modo, os efeitos impulsionadores do crescimento econômico comandado pela indústria deixam de acontecer em situação de desindustrialização precoce, trazendo, como consequência, a não ocorrência na melhoria da renda e do bem-estar na sociedade (COMIM, 2009). Nesse contexto, a desindustrialização precoce é um fenômeno que tem impacto negativo sobre o potencial de crescimento de longo prazo, pois reduz a geração de retornos crescentes, diminui o ritmo de progresso técnico e aumenta a restrição externa ao crescimento (LOURES et al., 2006).

Observa-se o fenômeno da desindustrialização em países desenvolvidos em um momento no qual experimentavam um nível de renda per capita em torno de US\$20.000. A Figura 5 ilustra a curva de desindustrialização dos países da OCDE, organização composta por países com elevado PIB per capita e IDH. Neste contexto, a perda de participação industrial não prejudica a expansão econômica desses países, pois a renda per capita segue trajetória crescente, mesmo com a diminuição do valor adicionado manufatureiro (FIESC, 2014).

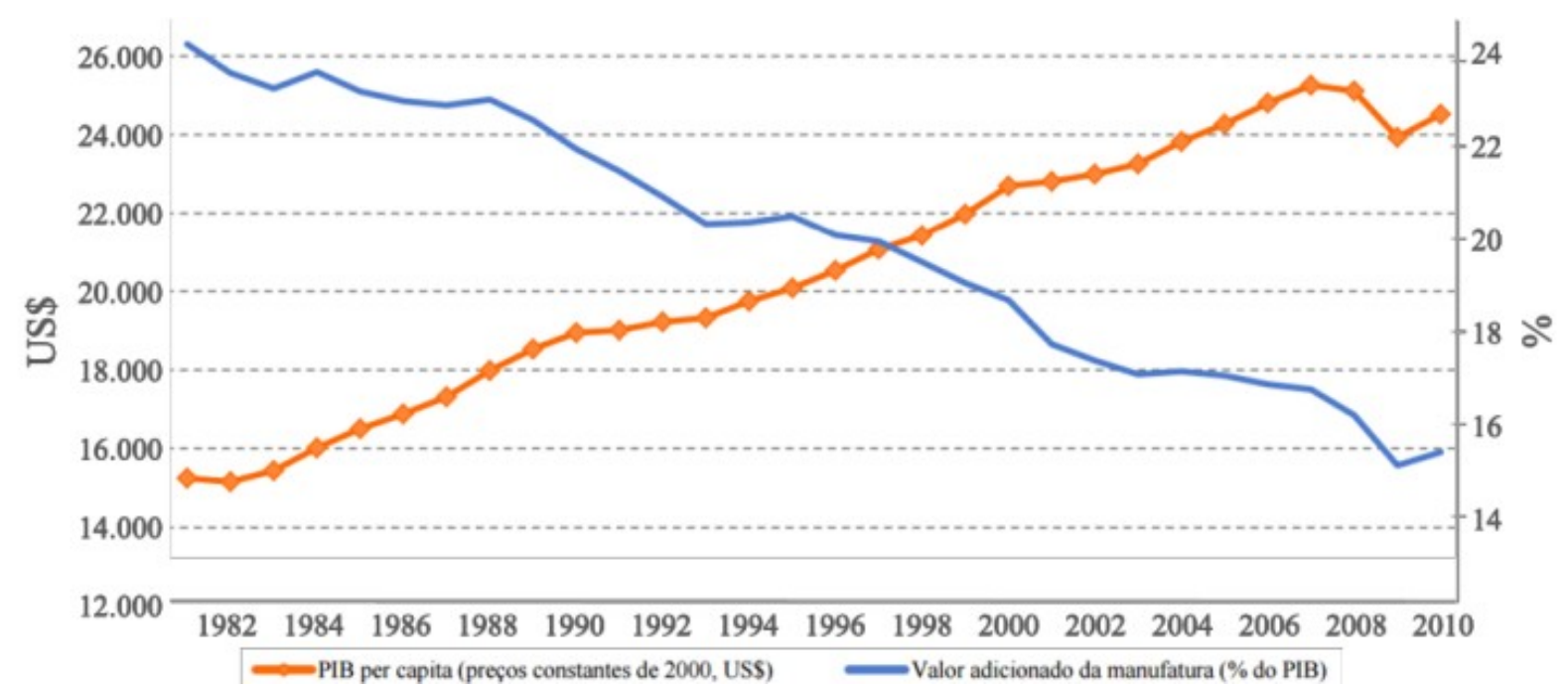

Figura 5: PIB per capita dos países da OCDE e o Valor Adicionado da Indústria

Fonte: World Development Indicators (WDI, 2011)

O processo de desindustrialização em Santa Catarina acompanhou a tendência nacional. Este processo não é verificado de maneira homogênea entre os setores da indústria do estado. De uma forma geral, o estado de Santa Catarina passou por um processo de desindustrialização parcial, no qual algumas atividades do setor industrial se desindustrializaram, enquanto outras mostraram crescimento. Quando os valores totais do 
estado são confrontados, verifica-se perda de participação do setor industrial na composição do PIB sem que a participação da indústria na parcela de emprego no estado não decresceu. Deduz-se, portanto, que o processo de desindustrialização do estado pode ser considerado relativo (FIESC, 2014).

\section{PROCEDIMENTO METODOLÓGICO}

Para atingimento dos objetivos propostos neste trabalho, definiu-se roteiro metodológico composto por quatro macroetapas:

i. levantamento e tratamento de dados;

ii. análise estatística dos dados da amostra e da literatura para identificar relações significativas;

iii. caracterização do cenário atual do setor industrial catarinense quanto ao processo de industrialização da Indústria 4.0;

iv. identificar os desafios e oportunidades da indústria catarinense com foco na Indústria 4.0.

A primeira macroetapa objetivou construir uma amostra consistente e representativa sobre o parque industrial abordado no trabalho. Na segunda macroetapa buscou-se, com o auxílio de técnicas estatísticas de mineração de dados, encontrar relações significativas entre dados coletados, assim como identificar tendências entre diferentes setores industriais e definir grupos que possuem características comuns no escopo da Indústria 4.0.

As duas últimas macroetapas objetivam identificar o panorama atual da indústria catarinense quanto ao uso das tecnologias digitais da Indústria 4.0. Buscam ainda, levantar os desafios e oportunidades do setor no processo de digitalização da indústria, comparandoos com países onde a manufatura avançada mostra maior desenvolvimento de forma a propor medidas que alavanquem o processo de digitalização do setor industrial catarinense.

A Figura 6 mostra o detalhamento das macroetapas em suas etapas e procedimentos na sequência aproximada de execução.

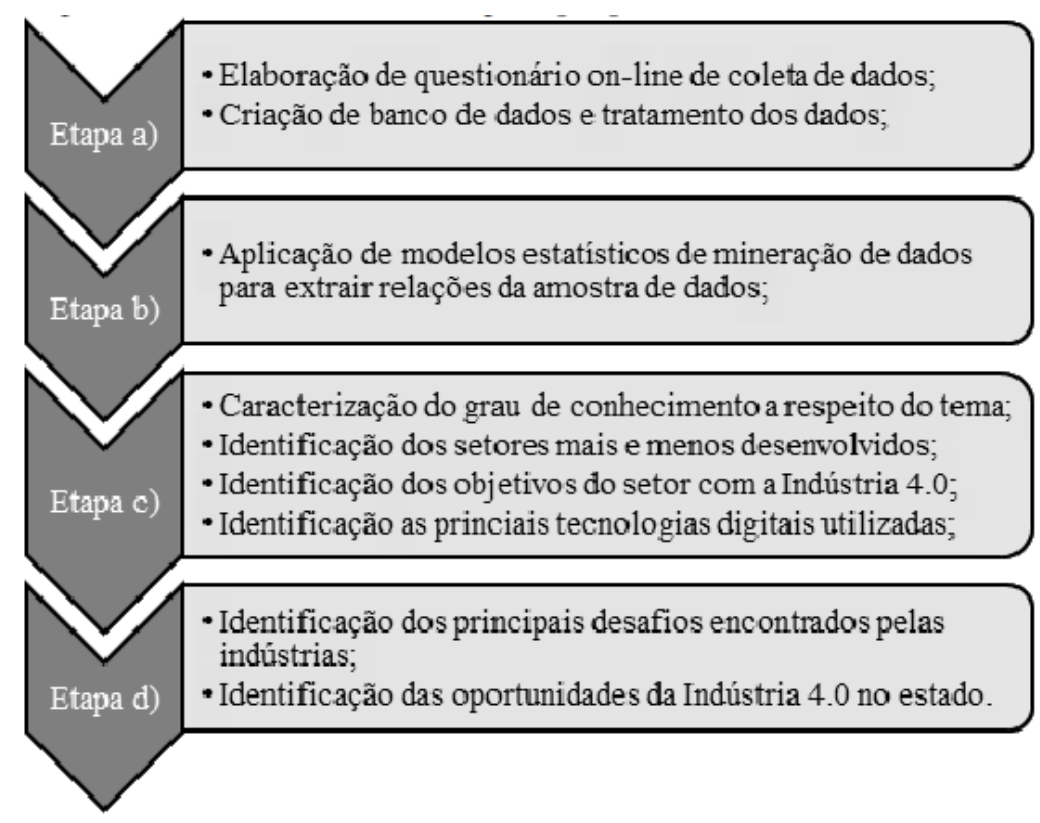

Figura 6: Roteiro metodológico

O questionário elaborado teve como principal objetivo identificar aspectos da Indústria 4.0 no setor industrial catarinense. Como o estudo não objetiva uma avaliação qualitativa através da definição de uma função resposta para o fenômeno da Indústria 4.0 no 
estado, as questões do formulário são de caráter exploratório. Estas, foram baseadas em pesquisas semelhantes, realizadas em países onde a temática da manufatura avançada já está consolidada.

O questionário desenvolvido e aplicado foi dividido em cinco partes:

i. $\quad$ introdução explicativa sobre a Indústria 4.0

ii. validação e caracterização dos dados da pesquisa

iii. conhecimentos gerais sobre a Indústria 4.0

iv. $\quad$ ações específicas da empresa com foco na Indústria 4.

v. competitividade geral do setor industrial.

Desta forma criou-se uma base de dados das empresas catarinenses que pode ser diretamente comparada com outras experiências da manufatura digital, servindo, também, como um parâmetro para classificar o setor industrial do estado frente a países desenvolvidos.

Primeiramente, questionou-se sobre a região na qual a empresa está localizada. Para determinar o espaço amostral dessa questão, utilizou-se a divisão do estado em mesorregiões, conforme determinação do IBGE. Um campo adicional foi criado, para selecionar as empresas que não possuem unidades fabris em Santa Catarina, porém estão respondendo a pesquisa. O número de empresas que foram excluídas da análise por conta desse item foram cinco. A Tabela 1 apresenta estes resultados. Além do critério de validação dos dados, outra informação importante que essa questão traz é a geolocalização do dado. Assim, pode-se mapear as empresas em relação às mesorregiões de Santa Catarina e inferir conclusões relevantes sobre a amostra de dados.

\begin{tabular}{lc}
\hline Mesorregião de SC & Número de Respostas \\
\hline Vale do Itajaí & 27 \\
Norte Catarinense & 15 \\
Grande Florianópolis & 13 \\
Serrana & 11 \\
A empresa não possui unidade em Santa Catarina & 5 \\
Sul Catarinense & 8 \\
Oeste Catarinense & 7 \\
\hline Total & 86 \\
\hline
\end{tabular}

Tabela 1: Distribuição e geolocalização dos dados da pesquisa nas mesorregiões de Santa Catarina

A plataforma utilizada para a aplicação do formulário, assim como sua criação, foi o Google Forms. O período de coleta de dados teve duração de 34 dias, com início em abril de 2017. A divulgação da pesquisa para o público-alvo, isto é, empresas do setor industrial catarinense, foi feita através de e-mails direcionados para as empresas-alvo e também através de uma parceria com a Associação Brasileira de Internet Industrial (ABII), a qual divulgou a pesquisa para seus membros no estado de Santa Catarina e colaborou com a aquisição de dados para o desenvolvimento do presente trabalho. A definição do público-alvo foi feita de acordo com o caderno da FIESC-Santa Catarina em Dados (2015), no qual as empresas de maior destaque no estado são listadas. Assim, definiu-se essas empresas como sendo o público-alvo principal da pesquisa, sendo composta por 180 empresas. Porém, outras plataformas de comunicação foram utilizadas para divulgar a pesquisa e coletar o maior número de dados.

Modelos preditivos baseados em árvore de decisão preconizam a definição de uma variável dependente, que a partir desta, a estrutura em forma de árvore binária é construída. Quatro variáveis ("Impacto Competitividade”, “Customização”; "Estratégia I4.0” e "Grau 
I4.0") foram selecionadas sendo que "Grau I4.0" foi definida a partir do número de observações no uso das tecnologias digitais pelas empresas. Esta variável tem valores em uma escala ordinal associados de acordo com as seguintes categorias:

i. Nenhum: nenhuma tecnologia digital assinalada;

ii. Baixo: 1 ou 2 tecnologias digitais assinaladas pela empresa;

iii. Médio: 3 ou 4 tecnologias digitais assinaladas pela empresa;

iv. Alto: 5 a 7 tecnologias digitais assinaladas pela empresa;

v. Elevado: 8 ou 9 tecnologias digitais assinaladas pela empresa.

De acordo com o grau de assertividade do modelo de árvore desenvolvida, selecionaram-se duas delas para compor variável dependente do modelo. A assertividade do modelo está baseada no número de casos falso-verdadeiro que são identificados. Esses casos representam o número de previsões erradas que a árvore faz, quando comparado aos dados observados na amostra. As variáveis escolhidas como dependentes para constituição de modelos preditivos foram "Grau I4.0" e "Impacto Competitividade” por apresentarem maior valor de assertividade entre as possíveis candidatas (Tabela 2).

\begin{tabular}{ccccc}
\hline Modelo & $\begin{array}{c}\text { Variável } \\
\text { dependente }\end{array}$ & $\begin{array}{c}\text { Número de falso- } \\
\text { verdadeiro }\end{array}$ & $\begin{array}{c}\text { Número de } \\
\text { verdadeiro- } \\
\text { verdadeiro }\end{array}$ & $\begin{array}{c}\text { Assertividade do } \\
\text { modelo }\end{array}$ \\
\hline 1 & $\begin{array}{c}\text { Grau I4.0 } \\
\text { Impacto }\end{array}$ & 17 cases & 64 cases & $79,01 \%$ \\
2 & Competitividade & 31 cases & 50 cases & $61,72 \%$ \\
\hline 3 & Customização & 33 cases & 48 cases & $59,25 \%$ \\
4 & Estratégia I4.0 & 45 cases & 36 cases & $44,44 \%$ \\
\hline
\end{tabular}

Tabela 2: Seleção da variável dependente do modelo

\section{DESENVOLVIMENTO E ANÁLISE DOS RESULTADOS}

As próximas seções estão reservadas à análise do cenário corrente quanto ao uso das tecnologias digitais pela indústria catarinense. Inicialmente são apresentados os tipos de tecnologias digitais que as empresas estão empregando e o quanto dessas tecnologias estão integradas no sistema produtivo. Na sequência são apresentados os resultados de modelos preditivos obtidos por meio do conceito de árvore de decisão derivado do método CART (Classification And Regression Trees) (BREIMAN et al., 1984).

\subsection{USO DAS TECNOLOGIAS DIGITAIS PELO SETOR INDUSTRIAL CATARINENSE E INTEGRAÇÃO COM AS NECESSIDADES DO CLIENTE}

A Tabela 3 mostra os tipos de tecnologias usados pelo setor industrial catarinense. Observa-se que o foco fica bem dividido entre sistemas aplicados ao processo e outros, aplicados ao produto. Embora os valores estejam bem distribuídos entre esses dois focos, observou-se que o setor industrial do estado busca nas tecnologias da Indústria 4.0, preferencialmente, benefícios em eficiência e produtividade (processos). Contudo, o fato de as tecnologias voltadas a produto ganharem destaque na pesquisa $(42,0 \%$ das empresas utilizam Cloud e 19,8\% Big Data) sugere, em uma primeira análise, que as empresas do setor industrial catarinense estão, também, se preparando para atender as necessidades dos clientes.

Aprofundando a análise na indústria catarinense, pode-se constatar que as tecnologias mais utilizadas são os sistemas Cloud e MES (Manufacturing Execution Systems) /SCADA (Supervisory Control and Data Acquisition). Estas tecnologias digitais possuem aplicabilidade para a maioria dos setores industriais, não sendo restritas a 
manufaturas específicas. Essa característica, aliada aos menores custos de implementação, quando comparadas às demais tecnologias digitais da Indústria 4.0, esclarece a predominância do uso desses sistemas.

A Tabela 4 relaciona as tecnologias digitais às características das empresas pesquisadas. Nesta tabela estão relacionadas características do tamanho da empresa (pelo número de funcionários e faturamento bruto anual) e do capital controlador. Ela mostra o percentual de uso das tecnologias digitais listadas em relação ao tipo de empresa. Uma observação geral dos dados evidencia que o uso das tecnologias digitais é mais frequente em empresas de médio e grande porte em relação ao número de funcionários.

\begin{tabular}{|c|c|c|}
\hline Estágio/Foco & Tecnologia & Uso (\%) \\
\hline \multirow{3}{*}{ Processo } & $\begin{array}{l}\text { Smart Sensors - Automação digital com sensores para } \\
\text { controle de processo }\end{array}$ & $22,2 \%$ \\
\hline & $\begin{array}{l}\text { Monitoramento e controle remoto da produção com } \\
\text { sistemas do tipo MES (Manufacturing Execution } \\
\text { Systems) e SCADA (Supervisory Control and Data } \\
\text { Acquisition) }\end{array}$ & $30,9 \%$ \\
\hline & $\begin{array}{l}\text { Sistemas de Produção Ciber-Físicos (Cyber-Physical } \\
\text { Production Sistems) }\end{array}$ & $4,9 \%$ \\
\hline \multirow{3}{*}{$\begin{array}{l}\text { Desenvolvimento/ } \\
\text { redução time to } \\
\text { market }\end{array}$} & $\begin{array}{l}\text { Sistemas integrados de engenharia para } \\
\text { desenvolvimento de produtos e manufatura de produtos }\end{array}$ & $17,3 \%$ \\
\hline & Manufatura aditiva - impressão 3D & $4,9 \%$ \\
\hline & Sistemas de Realidade Aumentada & $2,5 \%$ \\
\hline \multirow{3}{*}{$\begin{array}{l}\text { Produto/ novos } \\
\text { modelos de } \\
\text { negócio }\end{array}$} & $\begin{array}{l}\text { Big Data - Coleta, processamento e análise de grandes } \\
\text { quantidades de dados }\end{array}$ & $19,8 \%$ \\
\hline & $\begin{array}{l}\text { Cloud - Utilização de serviços em nuvem associados ao } \\
\text { produto }\end{array}$ & $42,0 \%$ \\
\hline & $\begin{array}{l}\text { Internet das Coisas (IoT) e Product Service Systems - } \\
\text { Incorporação de serviços digitais nos produtos }\end{array}$ & $11,1 \%$ \\
\hline $\begin{array}{l}\text { Nenhuma das } \\
\text { anteriores }\end{array}$ & & $21,0 \%$ \\
\hline Não soube dizer & & $6,2 \%$ \\
\hline
\end{tabular}

Tabela 3 - Uso das tecnologias digitais pelo setor industrial em Santa Catarina

Nota: a soma dos percentuais supera $100 \%$ devido a possibilidade de múltiplas respostas

Enquanto observa-se que algumas empresas têm alinhado estratégias com a Indústria 4.0 e consequentemente investido em tecnologias digitais. Constata-se, por outro lado, que um grande número de tecnologias está distante deste patamar.

\begin{tabular}{|c|c|c|c|c|c|c|c|c|c|}
\hline \multirow[b]{2}{*}{ Tecnologia Digital I4.0 } & \multicolumn{3}{|c|}{$\begin{array}{c}\text { Tamanho - Número de } \\
\text { funcionários }\end{array}$} & \multicolumn{3}{|c|}{ Capital controlador } & \multicolumn{3}{|c|}{$\begin{array}{c}\text { Tamanho - Faturamento Bruto } \\
\text { anual }\end{array}$} \\
\hline & Pequena & Média & Grande & Nacional & Estrangeiro & $\begin{array}{l}\text { Nacional e } \\
\text { estrangeiro }\end{array}$ & Pequena & Media & Grande \\
\hline Big Data & $6 \%$ & $17 \%$ & $33 \%$ & $14 \%$ & $0 \%$ & $33 \%$ & $12 \%$ & $13 \%$ & $35 \%$ \\
\hline $\begin{array}{l}\text { Sistemas integrados de } \\
\text { engenharia }\end{array}$ & $13 \%$ & $14 \%$ & $29 \%$ & $16 \%$ & $33 \%$ & $20 \%$ & $8 \%$ & $21 \%$ & $24 \%$ \\
\hline $\operatorname{MES} / \operatorname{SCADA}(*)$ & $3 \%$ & $31 \%$ & $67 \%$ & $21 \%$ & $67 \%$ & $60 \%$ & $8 \%$ & $28 \%$ & $65 \%$ \\
\hline IoT & $6 \%$ & $17 \%$ & $10 \%$ & $11 \%$ & $33 \%$ & $7 \%$ & $8 \%$ & $18 \%$ & $0 \%$ \\
\hline Manu fatura Aditiva & $0 \%$ & $7 \%$ & $10 \%$ & $5 \%$ & $33 \%$ & $0 \%$ & $0 \%$ & $5 \%$ & $12 \%$ \\
\hline Cloud & $29 \%$ & $55 \%$ & $38 \%$ & $38 \%$ & $67 \%$ & $47 \%$ & $28 \%$ & $51 \%$ & $35 \%$ \\
\hline $\begin{array}{l}\text { Sistemas de Produção Ciber- } \\
\text { Físicos }\end{array}$ & $0 \%$ & $7 \%$ & $10 \%$ & $3 \%$ & $33 \%$ & $7 \%$ & $0 \%$ & $8 \%$ & $6 \%$ \\
\hline Realidade aumentada & $0 \%$ & $3 \%$ & $5 \%$ & $3 \%$ & $0 \%$ & $0 \%$ & $0 \%$ & $3 \%$ & $6 \%$ \\
\hline Smart Sensors & $0 \%$ & $24 \%$ & $52 \%$ & $17 \%$ & $33 \%$ & $40 \%$ & $4 \%$ & $26 \%$ & $41 \%$ \\
\hline
\end{tabular}

Tabela 4: Relação entre o uso das tecnologias digitais e as características das empresas pesquisadas 


\subsection{MODELOS PREDITIVOS PARA O PANORAMA DA INDÚSTRIA 4.0 EM SANTA CATARINA}

A partir da seleção das variáveis dependentes e independentes, da determinação dos parâmetros e critérios do modelo de árvore de decisão e da interpretação dos resultados obtidos, selecionou-se dois modelos preditivo da Indústria 4.0 em Santa Catarina. A árvore obtida com o modelo considerando como variável dependente o 'Grau I4.0', descrito na seção anterior, é mostrada na Figura 7 e descrita na sequência.

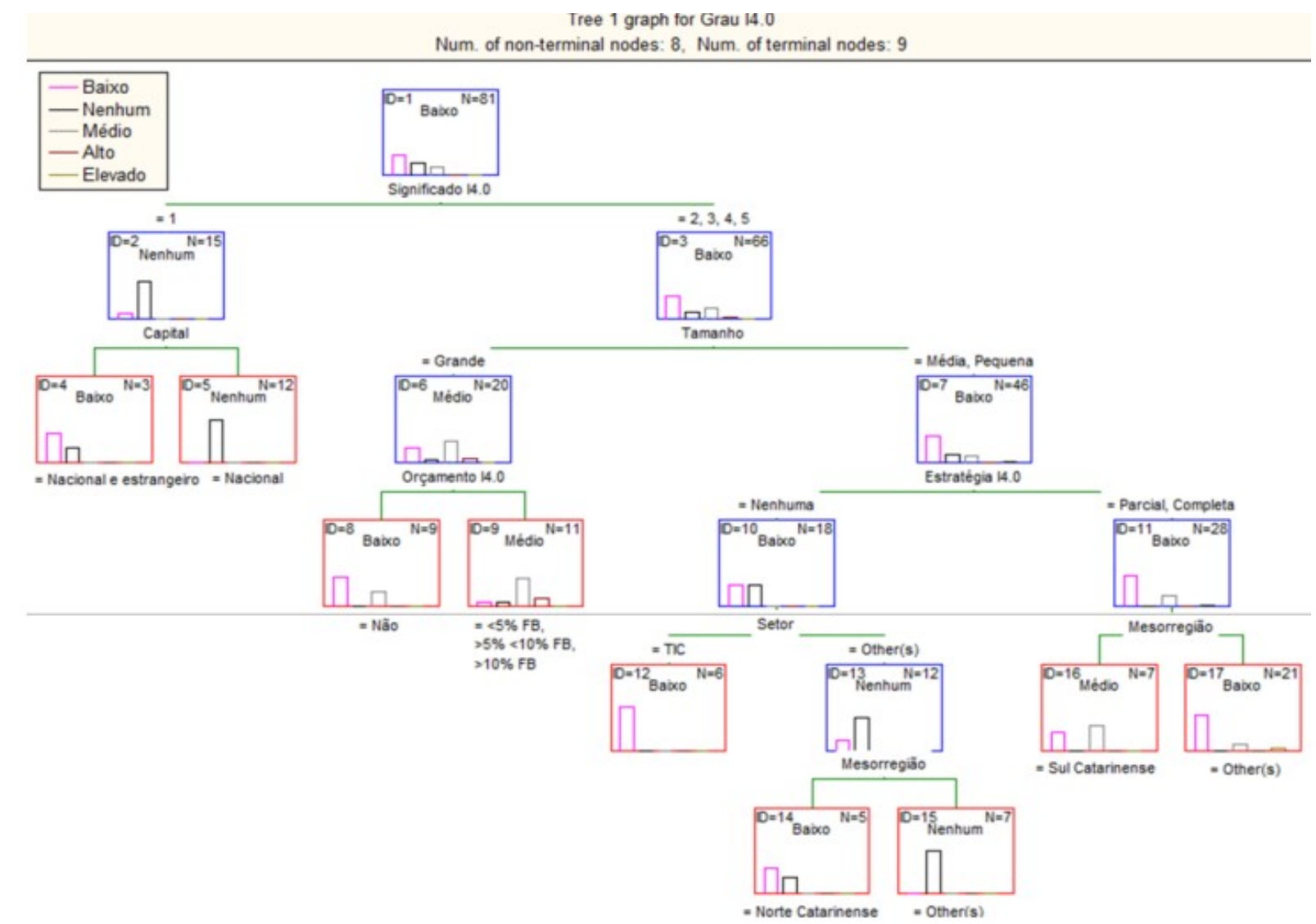

Figura 7: Modelo de árvore de decisão para a variável 'Grau I4.0’

A variável Grau 4.0 foi definida de acordo com o número de tecnologias digitais que as empresas utilizam, constituindo-se de uma escala ordinal que pode assumir valores desde 'Nenhum' até 'Elevado'. A primeira regra obtida com essa árvore mostra que empresas de capital exclusivamente nacional, nas quais a Indústria 4.0 não é nem será tema para a empresa não possuem qualquer tipo de tecnologia digital empregado no seu negócio. Em um primeiro momento essa regra da árvore de decisão pode parecer intuitiva, porém ela mostra que uma grande parcela da indústria catarinense não irá desenvolver-se tecnologicamente e está fadada a perder continuamente espaço no mercado. Outras empresas nas quais a Indústria 4.0 também não será tema, porém são de capital misto (nacional e internacional) apresentam um grau tecnológico maior, devido unicamente ao caráter internacional da empresa. Isso mostra como a pressão dos mercados internacionais, muito mais competitivos que os mercados nacionais, impõem um uso maior das tecnologias digitais, mesmo que de forma inconsciente para a empresa. Outra regra derivada da árvore de decisão mostra que empresas de grande porte que possuem um orçamento (2017) destinado à Indústria 4.0 empregam muito mais tecnologias digitais do que empresas do mesmo tamanho que não vão investir em tecnologia em 2017. Assim, o perfil de investimento das empresas de grande porte para os próximos anos define o grau de utilização das tecnologias digitais, e 
consequentemente, o nível de digitalização da empresa. Entre as empresas de pequeno e médio porte que não possuem uma estratégia definida para a Indústria 4.0, o único setor que identifica uso de tecnologias digitais é o setor de Tecnologia da Informação e Comunicação (TIC). Empresas desse setor são, por natureza, mais digitalizadas que outros setores. Sob o ponto de vista regional do estado, a mesorregião do Norte Catarinense ganha destaque entre as empresas que não possuem uma estratégia para a Indústria 4.0. Esta região apresenta intensidade de uso das tecnologias digitais acima das demais (podendo registrar o uso de até duas tecnologias), enquanto que as empresas das outras regiões não utilizam nenhuma. Como regra geral deste ramo da árvore de decisão, pode-se afirmar que o setor de TIC é, por natureza, o mais tecnológico e está alinhado geograficamente com a mesorregião do Norte Catarinense. Por fim, como última regra dessa árvore de decisão, tem-se as empresas de médio e pequeno porte que afirmam já possuir uma estratégia para a Indústria 4.0. Nesse grupo, destaca-se a mesorregião do Sul Catarinense como a mais digitalizada. Isso demostra, que as empresas dessa mesorregião são as mais desenvolvidas quanto ao uso das tecnologias digitais da amostra de dados pesquisada. Assim, como observado, o fato de a empresa possuir ou não uma estratégia para a Indústria 4.0 faz com que a mesorregião de destaque oscile entre o Norte e Sul Catarinense.

Outro modelo preditivo na forma de árvore ganhou destaque no presente trabalho devido ao seu grau de assertividade. A árvore obtida com o modelo considerando a variável "Impactos Competitividade” é mostrada na Figura 8.

Num. of non-terminal nodes: 8 , Num. of terminal nodes: 9

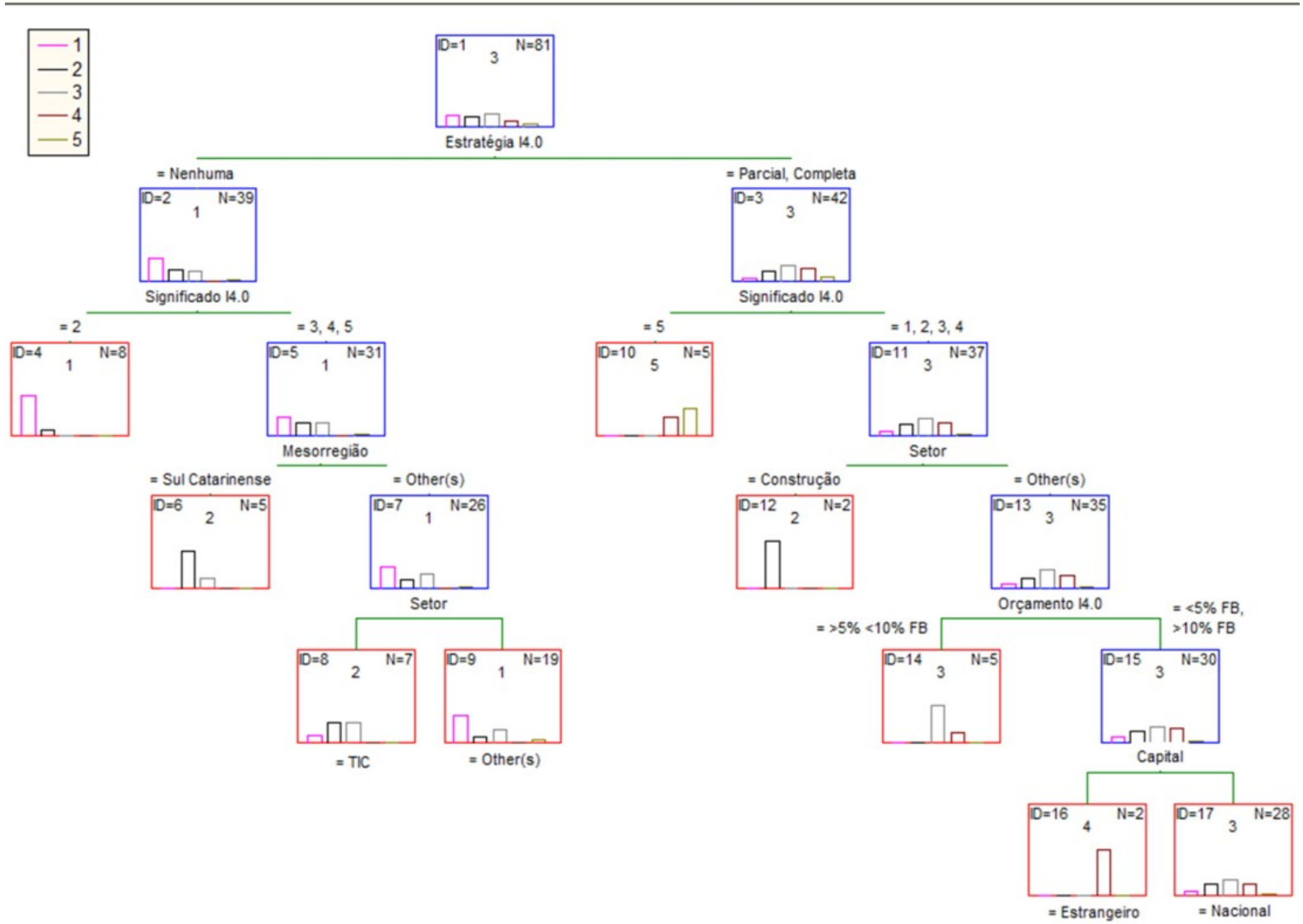

Figura 8 - Modelo de árvore de decisão para a variável "Impactos Competitividade”

A árvore formada na sua parte esquerda descreve uma regra que reforça a discussão feita anteriormente. Nessa regra, o setor TIC destaca-se dos demais pelo fato de sentir os 
impactos mais intensamente da competitividade do setor causado pelas tecnologias da Indústria 4.0. Quando ambas as árvores são analisadas, pode-se entender que tanto o setor de TIC, assim como a mesorregião do Sul Catarinense estão inseridas em um contexto mais competitivo, condicionando o desenvolvimento de um grau maior no uso das tecnologias digitais. Outra regra que surge na análise dessa árvore é que empresas que já possuem uma estratégia para a Indústria 4.0, podendo ser parcial (para setores isolados da empresa) ou total (para todos os setores da empresa) apresentam conceitos da Indústria 4.0 inseridos na cultura da empresa pois atuam em mercados mais competitivos. De uma forma geral, podese afirmar que as empresas que dispõem de estratégia e cultura voltada para a Indústria 4.0, o fazem porque estão inseridas em mercados altamente competitivos onde a digitalização já mostra grandes impactos. Dando continuidade à sequência da árvore, pode-se destacar o setor de construção como um setor de baixo risco, pois os impactos em competitividade da Indústria 4.0 ainda não são percebidos.

\subsection{DESAFIOS E OPORTUNIDADES DA INDÚSTRIA 4.0 EM SANTA CATARINA}

Foram pré-definidas possíveis causas para as dificuldades encontradas pelas empresas, sendo estas baseadas em literatura pertinente. Assim, pode-se construir o gráfico representado pela Figura 9. Percebe-se que as 'barreiras' à digitalização da indústria identificadas pelos entrevistados são bastante heterogêneas. Como destaque, pode-se citar o Alto Custo de Implementação e a Infraestrutura de TI inapropriada e como os principais entraves à Indústria 4.0 , sendo identificados por $42 \%$ e $35,8 \%$ das empresas, respectivamente. Outro item que merece destaque principal, já que consiste em um problema crônico do Brasil, é a escassez de mão de obra qualificada, sendo opção de 33,3\% das empresas pesquisadas.

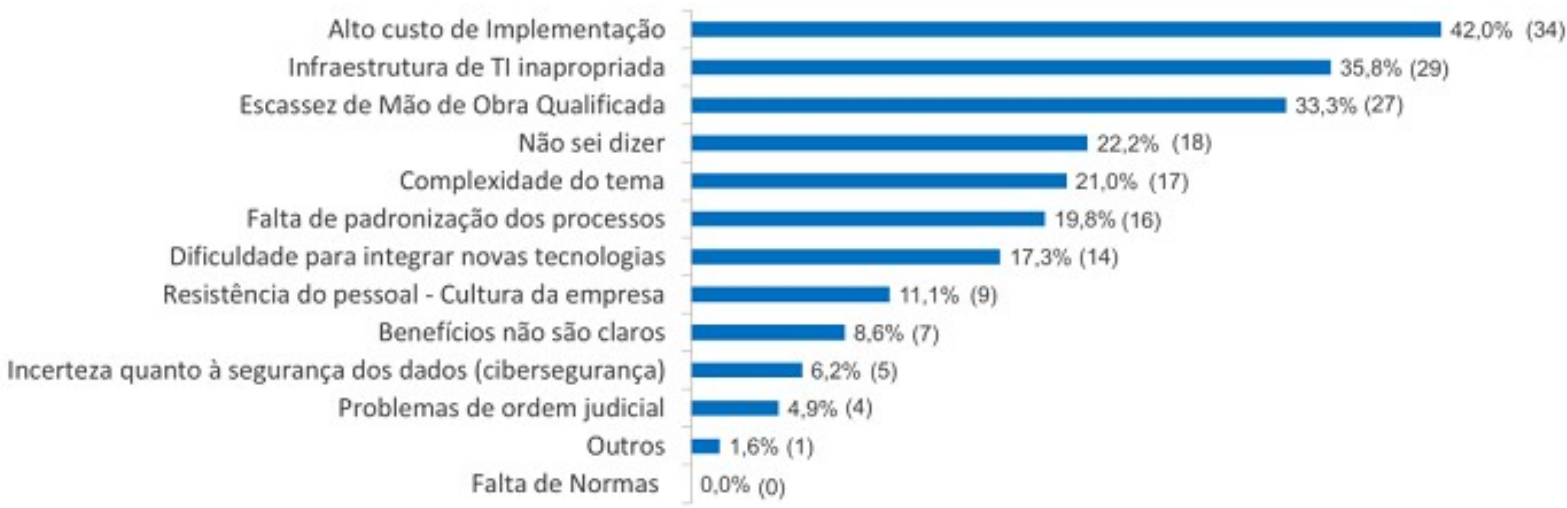

Figura 9: Principais desafios para a digitalização da indústria catarinense

Grande parte das indústrias catarinenses afirma não possuir um suporte de TI adequado para ambientar as tecnologias da Indústria 4.0. A manufatura avançada requer que diversos sistemas sejam conectados e sejam hábeis em se comunicar uns com os outros. De acordo com Schaepfer e Koch (2016), as empresas devem inicialmente avaliar o estado atual dos seus sistemas e conhecer suas limitações para evitar que estejam nem superdimensionados e nem insuficientes para as aplicações desejadas.

\section{CONCLUSÕES}

O objetivo geral deste trabalho foi caracterizar o estado atual da Indústria 4.0 no setor industrial catarinense, identificando os desafios e as oportunidades para o setor nesse 
processo de digitalização da indústria. Para tanto foram aplicadas técnicas estatísticas e de mineração de dados através de modelos de árvore de decisão.

Inicialmente, identificou-se que $12 \%$ das empresas pesquisadas não possui qualquer conhecimento sobre a Indústria 4.0. Quando comparado a países referência em industrialização, percebe-se que o estado está atrasado no desenvolvimento dos conceitos da Indústria 4.0. Da parcela das empresas que já conhecem a manufatura avançada, aproximadamente $70 \%$ afirmam que já utilizam ou possuem ações de curto prazo para implementar as tecnologias digitais. A maioria dessas empresas prometiam comprometer até 5\% do seu faturamento bruto em investimentos na Indústria 4.0 em 2017.

As empresas entrevistadas procuram na Indústria 4.0 a redução dos custos de produção e a otimização do uso da capacidade produtiva. As principais tecnologias utilizadas pelo setor são os sistemas de monitoramento tipo MES, SCADA, Cloud e Big Data. Como principais desafios encontrados no processo de digitalização da indústria estão a infraestrutura de TI inapropriada, alto custo de implementação das tecnologias digitais e escassez de mão de obra qualificada.

As grandes oportunidades do estado catarinense no auxílio às empresas está em possibilitar troca de experiências e contato com parceiros nacionais e internacionais e na formação de mão de obra qualificada que saiba lidar com as tecnologias das fábricas digitais. Os segmentos da empresa eleitos pelos entrevistados como os que possuem maior potencial para desenvolvimento através das tecnologias da Indústria 4.0 são Produção e Qualidade. As áreas de Engenharia e Logística/Armazém também receberam destaque como potenciais segmentos para implementação de técnicas da Indústria 4.0.

\section{REFERÊNCIAS BIBLIOGRÁFICAS}

[1] BREIMAN, L.; FRIEDMAN, J. H.; OLSHEN, R. A.; STONE, C. J. Classification and Regression Trees. Wadsworth, 1984.

[2] COMIN, A. A desindustrialização truncada: perspectivas do desenvolvimento econômico brasileiro. 2009. 271 f. Tese (Doutorado) - Curso de Economia, Economia, Universidade Estadual de Campinas, Campinas, 2009.

[3] FIESC. Santa Catarina em Dados. 2015. Disponível em: <http://fiesc.com.br/tecnologia-e-inovacaoAcesso em: 07 mar. 2018.

[4] FIESC. Processo de Desindustrialização em Santa Catarina. 2014. Disponível em: $<$ http://fiesc.com.br/tecnologia-e-inovacao>. Acesso em: 04 mar. 2018.

[5] GEISSBAUER, R.; SCHRAUF S.; KOCH, V.; KUGE, S. Industrie 4.0: Chance und Herausforderung der vierten industriellen Revolution. Strategy\&. PWC, München, 2016. Disponível em <https://www.strategyand.pwc.com/media/file/Industrie40.pdf.> Acessado em 04 maio 2018.

[6] IBGE. Pesquisa Industrial de Inovação Tecnológica. 2016. Disponível em: <http://www.ibge.gov.br/home/estatistica/economia/industria/pintec/ metodologia.shtm>. Acesso em: 15 mar. 2018.

[7] LOURES, R.R; OREIRO, J.L; PASSOS, C.A.K. Desindustrialização: a crônica da servidão consentida. Economia e Tecnologia, Ano 2, Vol. 4, 2006.

[8] ROBERT BOSCH. Industrie 4.0: The next Industrial Revolution. 2016. Disponível em: $\quad<$ https://www.boschsi.com/de/loesungenfertigungsindustrie/industrie-4-0/ industrie-4-0.html>. Acesso em: 8 jun. 2016. 
[9] SCHLAEPFER, R.; KOCH, M. Industry 4.0: Challenges and solutions for the digital transformation and use of exponential technologies. Deloitte, Zurique, 2015. Disponível em $<$ http://www2.deloitte.com/content/dam/Deloitte/ch/Documents/manufacturing/ch-enmanufacturing-industry-4-0-24102014.pdf> Acessado em 04 maio 2018.

[10] TREGENNA, F. Characterizing deindustrialization: an analysis of changes in manufacturing employment and output internationally. Cambridge Journal of Economics, vol. 33, 2009.

[11] WANG, S.; WAN, J. et al. Implementing Smart Factory of Industrie 4.0: An Outlook. International Journal of Distributed Sensor Networks, Guangzhou, 27 abr. 2015. Disponível em <http://www.hindawi.com/journals/ijdsn/2016/3159805/cta/>. Acessado em 04 maio 2018.

[12] WDI. World Development Indicators, World Bank collection of development indicators. 2011. Disponível em: <http://data.worldbank.org/data-catalog/worlddevelopment-indicators>. Acesso em: 22 abril 2019.

[13] ZEZULKA, F; MARCON, P.; VESELY, I.; SAJDL, O. Industry 4.0 - An Introduction in the phenomenon. IFAC-PapersOnLine, vol. 49, no. 25, pp. 8-12, 2016. 